\title{
Death in Transitional Asia: 11-Year All-Cause Mortality in the Thai Cohort Study
}

\author{
Matthew J. Kelly ${ }^{1}$, Chalapati Rao ${ }^{1}$, Sam-ang Seubsman ${ }^{2} \&$ Adrian C. Sleigh ${ }^{1}$ \\ ${ }^{1}$ Department of Global Health, Research School of Population Health, Australian National University, Canberra, \\ Australia \\ ${ }^{2}$ School of Human Ecology, Sukhothai Thammathirat Open University, Canberra, Australia \\ Correspondence: Matthew Kelly, RSPH, 62 Mills Rd, ANU, Canberra 2602, Australia. Tel: 61-2-6125-0714. \\ E-mail: matthew.kelly@anu.edu.au
}

Received: November 23, 2018 Accepted: December 10, 2018 Online Published: March 7, 2019

doi:10.5539/gjhs.v11n4p1

URL: https://doi.org/10.5539/gjhs.v11n4p1

\begin{abstract}
Objective: Thailand is experiencing a substantial reduction in overall mortality, an ageing society and increasing prevalence of non-communicable diseases. There is an urgent need to understand locally important risk factors for this new disease burden and their distribution. We investigated risk factors for mortality in a large cohort of Thai adults and report on key trends.
\end{abstract}

Participants: A nationwide cohort of 87,151 Thai adults followed up since 2005 with their data records linked to the Thai civil registration system to monitor mortality up to the end of 2016.

Methods: We used logistic regression models to measure associations between a large range of socio-demographic, health behaviour and health status variables and all-cause mortality.

Results: 1402 cohort members died between 2005 and 2016. In fully-adjusted models higher income, female sex, and higher education had the strongest protective effects against mortality. Normal body weight also protected (AOR 0.71 [0.52-0.96] with Obese as reference). Heavy smoking (AOR 1.48 [1.29-1.70]), and regular alcohol consumption (AOR 1.37 [1.12-1.68]) were associated with the highest mortality. Experiencing injury in the year proceeding the baseline survey also associated with increased mortality, while urbanising since childhood had a protective effect.

Conclusion: This study adds to evidence regarding risks for all-cause mortality in Thailand. Results indicate the need for Thailand to maintain successful tobacco control programs and to address the effects of increased alcohol consumption. The protective effect of higher education is particularly important in Thailand given the growing proportion of the population who are finishing high school and moving to higher education.

Keywords: cohort study, Thailand, mortality, risk factors

\section{Introduction}

Over the last 4 decades, Thailand has experienced large reductions in overall mortality. Better nutrition, sanitation and health services, particularly primary health care, have significantly reduced the burden of infectious disease and maternal and child deaths. More recently with economic development, an ageing society and changing lifestyles, Thailand is facing a transition in disease patterns and causes of death. Non-communicable diseases including diabetes, stroke, ischaemic heart disease, liver and lung cancer are now leading causes of death. To inform health policy and health resource allocation in such a transitional context it is important to understand the locally relevant risk factors associated with premature mortality. The need for empirical, local, timely data on these risks is important; national health policy will be best informed by locally relevant data (Mahapatra et al., 2007) as particular patterns of lifestyle and environmental factors will vary by setting.

There is little information on risk factors and their interactions contributing to all-cause mortality in Thailand today. Studies which have addressed all-cause mortality in Thailand have in general focused on a single cluster of risk factors. Thus information is available on environmental (Angkurawaranon, Wattanatchariya, Doyle, \& Nitsch, 2013; Tawatsupa, Dear, Kjellstrom, \& Sleigh, 2014) or geographic risks (Faramnuayphol, Chongsuvivatwong, \& Pannarunothai, 2008), or particular health conditions (Sritara et al., 2003; Tanomsup et al., 2007). The World 
Health Organization defines the leading global risks for mortality as high blood pressure, tobacco use, high blood glucose, insufficient physical activity and overweight (World Health Organization, 2009). Other large regional meta-analyses and systematic reviews have also identified excess BMI, low fitness, and healthy diets as important for mortality (Barry et al., 2014; Flegal, Kit, Orpana, \& Graubard, 2013; Knoops et al., 2004; Reedy et al., 2014). Large studies in the Asia-Pacific region reported a particularly protective effect of higher education on mortality compared to higher income settings (Woodward et al., 2015).

In now high income countries the prevalence of these common risk factors for non-communicable disease has decreased, while these same risk factors persist in low and middle income countries. In Southeast Asia, increases in high blood pressure and serum cholesterol and excess BMI have been particular concerns (Danaei et al., n.d.; Danaei et al., 2011; Farzadfar et al., 2011; Finucane et al., 2011). The various configurations of interacting risk factors in specific settings, mediated by cultural, environmental and economic factors, lead to diverse risk and disease patterns (Ezzati \& Riboli, 2013). For example smoking rates vary widely within the Asian region with $76 \%$ of Indonesian men being current smokers, whereas in Thailand the proportion is only $41 \%$, and India only $20 \%$ (World Health Organization, 2015). However other forms of tobacco consumption may be more prevalent in settings with lower smoking rates. Alcohol consumption and diet also show great diversity across settings. The need to understand the varying importance of established risk factors for mortality in particular settings is important for informing locally relevant health policy.

Here we present analyses of the effect of a large number of risk factors on all-cause mortality in transitional Thailand. We consider 3 main risk factor domains: socio-demographic factors; health risk behaviours (including smoking and drinking); and health status indicators (prevalent health conditions at baseline).

\section{Methods}

\subsection{Study Population and Data}

Data used in the analyses presented here derive from a long running longitudinal study of changing health risks and health outcomes in transitional Thailand; the Thai Cohort Study (Sleigh, Seubsman, Bain, \& Team, 2008). Participants in the study are adult distance-learning students, residing all over Thailand who were enrolled at Sukhothai Thammathirat Open University (STOU) at baseline. In 2005 a comprehensive 20-page mail-out health questionnaire was sent to all students of the university $(\mathrm{n}=200000)$ and 87151 responded forming the cohort. The baseline questionnaire (Appendix 1) covered a wide range of topics including socio-demographic information, standardised health status indicators (Short Form 8 and Kessler), health risk behaviours including smoking, drinking, physical activity, diet, social capital and injury and history of doctor diagnosed disease (23 conditions including diabetes, high cholesterol, hypertension, ischemic heart disease, stroke and kidney disease).

Cohort participants represented the student body of STOU and the general Thai population well for median age, sex, ethnicity, religion, modest income and geographic distribution (S.-a. Seubsman et al., 2011; S. Seubsman, Yiengprugsawan, \& Sleigh, 2012). Cohort members however are more highly educated than the general population with almost all participants having completed high school. This education attribute was important for achieving high participation and reporting accuracy of sophisticated information about their background, circumstances and health. A table comparing the cohort to the STOU student body and the general population is found in Appendix 2.

When joining the TCS all participants were asked to provide their Citizen Identification number (CID), a unique 13-digit identification used across all interactions with government. The list of CIDs for all cohort members is periodically checked against death records kept by the Thai Ministry of Interior to enable us to identify deceased cohort members and their date of death. The cause of death is then provided by the Ministry of Public Health according to the standard International Classification of Diseases (ICD 10) system. In the analyses presented here we consider deaths reported by the Ministry of Interior occurring between March 2005 and December 2016 $(n=1402)$. We note that the vital statistics kept by Thailand over the period of our study have been assessed for accuracy and completeness and found to capture $95 \%$ or more of deaths (Prasartkul \& Vapattanawong, 2006).

\subsection{Data Processing and Analysis}

Incoming questionnaires in 2005 were scanned and digitised using Scandevet intelligent character recognition software. Further data verification, correction and editing were completed using MySQL software. For epidemiological analysis we used SPSS (version 20).

The prime variable of interest is whether the cohort member died anytime between March 2005 and December 2016. We described the distribution of deaths by personal characteristics of the cohort member: age (5 categories), sex, life course residence (whether an urban or rural resident at 10 years of age and in 2005), region of residence, 
marital status, education level and monthly income (5 categories, in Thai baht, USD1=25 baht in 2005).

We then used logistic regression models to test associations of mortality with putative exposures from the 2005 baseline questionnaire. These included socio-demographic indicators -- age, sex, residence, income, education and marital status (single, partnered or married). Health-risk behaviours considered included smoking (ever smoking and number of cigarettes per day), alcohol consumption (whether occasional, regular, previous or never drinker and the number of drinks per day), diet (frequency of consumption of various food types and daily serves of fruits and vegetables), and physical activity (number of weekly sessions of strenuous, moderate, mild and housework exercise). Health status indicators comprised lifetime disease history, injury history (number of injuries in the last 12 months), body mass index category (calculated from self-reported height and weight), and self-rated health. We tested all of these variables for their associations with deceased status of participants and developed a final analytical model, mutually adjusted for all significant covariates and reported adjusted odds ratios (AOR) and $95 \%$ confidence intervals.

\subsection{Ethical Approval}

Informed written consent was obtained from all participants who were advised that they could withdraw or not participate in the study with no effect on their academic progress. Ethics approval was obtained from Sukhothai Thammathirat Open University Research and Development Institute (protocol 0522/10) and the Australian National University Human Research Ethics Committee (protocols 2004/344 and 2009/570).

\section{Results}

Over the period from March 2005 to November 2016 a total of 1402 members of the Thai Cohort Study died. Table 1 reports the distribution of these deaths among socio-economic and demographic groups. There was an excess of males among the dead group (69.8\% vs $44.9 \%$ in overall cohort). Also more likely to be in the dead group were rural dwellers, particularly those who had moved to rural areas since their childhood, those from the North and Northeast regions, older cohort members (particularly those aged over 40 years), those earning less than 3000 or more than 10000 baht per month and those currently married in 2005. To further examine predictors of all-cause mortality we then constructed multivariable logistic regression models for socio-economic/demographic factors, health behaviour variables and a variety of health status measures.

\subsection{Socio-Demographic Factors}

Table 2 shows multivariable odds ratios for participants dying within the observation period, by a variety of socio-economic factors. In initial unadjusted models females were almost three times less likely to be in the dead group as males, as were those with university degrees compared with junior high school as their highest education level. Those single or living with a partner were also less likely to be in the deceased group than married participants. In model 1 we then adjusted for the effects of age and sex as these had the strongest relationship with mortality risk. These adjustments actually changed the direction of the mortality risk of high income. A statistically significant monotonic dose response protective effect of income is now observed with the highest income group having the lowest odds of dying (AOR 0.39, CI 0.29-0.52). Higher education remains protective though the size of the effect has reduced for university degree holders from OR 0.38 to AOR 0.58 (CI 0.46-0.73). The effect of single marital status also changed direction after these adjustments with married status now being protective. Finally model 2 was constructed adjusting for the whole range of covariates which had significant associations with mortality risk. Model 2 made little difference to the Odds Ratios calculated in Model 1 indicating no further residual confounding. 
Table 1. Cohort characteristics by survival status

\begin{tabular}{|c|c|c|c|c|}
\hline \multirow{2}{*}{ Characteristic } & Alive & Dead & Total & \multirow{2}{*}{12 year cumulative mortality rate per 1000} \\
\hline & $\mathbf{N}(\%)$ & $\mathbf{N}(\%)$ & $\mathbf{N}(\%)$ & \\
\hline Total population & $85749(98.4)$ & $1402(1.6)$ & 87151 & 16.09 \\
\hline \multicolumn{5}{|l|}{ Sex } \\
\hline Male & $38507(44.9)$ & $978(69.8)$ & $39485(45.3)$ & 24.77 \\
\hline Female & $47234(55.1)$ & $424(30.2)$ & $47658(54.7)$ & 8.90 \\
\hline \multicolumn{5}{|l|}{ Lifecourse residence } \\
\hline Rural-rural & $37125(43.8)$ & $620(45.4)$ & $37445(43.9)$ & 16.56 \\
\hline Rural-urban & $27053(32.0)$ & $381(27.9)$ & $27434(31.9)$ & 13.89 \\
\hline Urban-rural & $3630(4.3)$ & $77(5.6)$ & $3707(4.3)$ & 20.77 \\
\hline Urban-urban & $16866(19.9)$ & $288(21.1)$ & $17152(19.9)$ & 16.79 \\
\hline \multicolumn{5}{|l|}{ Region of residence } \\
\hline Bangkok & $14631(17.2)$ & $232(16.7)$ & $14863(17.2)$ & 15.61 \\
\hline Central & $20871(24.5)$ & $295(21.2)$ & $21166(24.5)$ & 13.94 \\
\hline North & $15487(18.2)$ & $267(19.2)$ & $15754(18.2)$ & 16.95 \\
\hline North-east & $17708(20.8)$ & $330(23.7)$ & $18038(20.9)$ & 18.29 \\
\hline East & $5244(6.2)$ & $83(6.0)$ & $5327(6.2)$ & 15.58 \\
\hline South & $11109(13.1)$ & $185(13.3)$ & $11294(13.1)$ & 16.38 \\
\hline \multicolumn{5}{|l|}{ Age group } \\
\hline $15-19$ & $2474(2.9)$ & $25(1.8)$ & 2499 (2.9) & 10.04 \\
\hline $20-29$ & $43742(51.0)$ & $473(33.7)$ & $44215(50.7)$ & 10.69 \\
\hline $30-39$ & $26905(31.4)$ & $415(29.6)$ & $27320(31.4)$ & 15.19 \\
\hline $40-49$ & $10636(12.4)$ & $317(22.6)$ & $10953(12.6)$ & 28.94 \\
\hline $50+$ & $1973(2.3)$ & $172(12.3)$ & $2145(2.5)$ & 80.19 \\
\hline \multicolumn{5}{|c|}{ Income (monthly in baht) } \\
\hline$<=3000$ & $9187(11.0)$ & $187(13.9)$ & $9374(11.0)$ & 19.95 \\
\hline $3001-7000$ & $25933(31.0)$ & $329(24.5)$ & $26262(30.9)$ & 12.53 \\
\hline $7001-10000$ & $19526(23.4)$ & $272(20.3)$ & $19798(23.3)$ & 13.74 \\
\hline $10001-20000$ & $20206(24.2)$ & $364(27.1)$ & $20570(24.3)$ & 17.70 \\
\hline 20001-30000 & $5202(6.2)$ & $110(8.2)$ & $5312(6.3)$ & 20.71 \\
\hline $30000+$ & $3565(4.3)$ & 79 (5.9) & $3644(4.3)$ & 21.68 \\
\hline \multicolumn{5}{|l|}{ Marital status } \\
\hline Single & $44869(53.9)$ & $611(45.6)$ & $45480(53.8)$ & 13.43 \\
\hline Living with partner & $4291(5.2)$ & $64(4.8)$ & $4355(5.1)$ & 14.70 \\
\hline Married & 34086 (40.9) & $664(49.6)$ & 34750 (41.1) & 19.11 \\
\hline
\end{tabular}

Note. Bolded figures indicate statistically significant differences $(\mathrm{p}<0.05)$ between column proportions. 
Table 2. Socio-economic and demographic factors and all-cause mortality

\begin{tabular}{|c|c|c|c|}
\hline & OR & AOR Model 1 ALL [95\% CI]* & AOR Model 2 [95\%CI]** \\
\hline \multicolumn{4}{|l|}{ Sex } \\
\hline Male & 1 & 1 & 1 \\
\hline Female & $0.35[0.32-0.40]$ & $0.42[0.37-0.47]$ & $0.53[0.46-0.61]$ \\
\hline \multicolumn{4}{|l|}{ Income } \\
\hline$<3000$ & 1 & 1 & 1 \\
\hline $3-7000$ & $0.62[0.52-0.75]$ & $0.67[0.56-0.81]$ & $0.66[0.54-0.79]$ \\
\hline $7-10000$ & $0.68[0.57-0.83]$ & $0.63[0.52-0.77]$ & $0.63[0.52-0.78]$ \\
\hline $10-20000$ & $0.89[0.74-1.06]$ & $0.55[0.45-0.66]$ & $0.57[0.46-0.70]$ \\
\hline $20-30000$ & $1.04[0.82-1.32]$ & $0.41[0.32-0.53]$ & $0.43[0.33-0.57]$ \\
\hline $30000+$ & $1.09[0.84-1.4]$ & $0.39[0.29-0.52]$ & $0.40[0.29-0.55]$ \\
\hline \multicolumn{4}{|l|}{ Education } \\
\hline Junior high school & 1 & 1 & 1 \\
\hline High school & $0.49[0.40-0.61]$ & $0.79[0.63-0.98]$ & $0.77[0.61-0.97]$ \\
\hline Diploma certificate & $0.42[0.33-0.52]$ & $0.77[0.61-0.97]$ & $0.81[0.63-1.03]$ \\
\hline University degree & $0.38[0.30-0.48]$ & $0.58[0.46-0.73]$ & $0.53[0.46-0.61]$ \\
\hline \multicolumn{4}{|l|}{ Lifecourse residence } \\
\hline Rural-rural & 1 & 1 & 1 \\
\hline Rural-urban & $0.84[0.74-0.96]$ & $0.79[0.69-0.90]$ & $0.80[0.70-0.92]$ \\
\hline Urban-rural & $1.27[1.00-1.61]$ & $1.11[0.86-1.41]$ & $1.14[0.89-1.47]$ \\
\hline Urban-urban & $1.02[0.89-1.18]$ & $0.96[0.83-1.10]$ & $0.99[0.85-1.16]$ \\
\hline \multicolumn{4}{|l|}{ Marital status } \\
\hline Married & 1 & 1 & 1 \\
\hline Living with partner & $0.70[0.63-0.78]$ & $1.36[1.19-1.56]$ & $1.25[1.07-1.45]$ \\
\hline Single & 0.77 [0.59-0.99] & 1.29 [0.99-1.69] & $1.27[0.97-1.67]$ \\
\hline
\end{tabular}

* adjusted for sex and age only.

** adjusted for sex, age, education, BMI category, smoking status, self-rated health, injury history, drinking status, income and disease history (diabetes, heart disease, high cholesterol, stroke, high blood pressure).

\subsection{Health Behaviours}

The strongest associations found in our study between health behaviours and mortality were for heavy smoking (Table 3). After adjusting for confounders those who had ever smoked were one and a half times more likely to die than never smokers. Using light smokers (1 or less cigarettes per day) as the reference group, those who smoke more than 5 cigarettes per day experienced twice the mortality risk (AOR 2.37, CI 1.67-3.38) and heavy smokers $(>=30$ cigarettes per day) six times the risk (AOR 6.07, CI 3.58-10.30). In our initial unadjusted model being a regular or ex-alcohol drinker was associated with mortality risk when compared with occasional social drinkers, and the risk increased with additional daily alcohol consumption. Never drinkers had lower odds of mortality (OR 0.80 , CI 0.69-0.92). In the fully adjusted model regular (AOR 1.37, CI 1.12-1.68) and ex-drinkers (AOR1.44, CI 1.22-1.70) still had significantly increased risks of mortality. The protective effect of being a never drinker though had disappeared. Other health risk behaviours were examined including physical activity and dietary factors but none of these were found to have an association with risk of death (data not shown). 
Table 3. Health Behaviours and all-cause mortality

\begin{tabular}{|c|c|c|c|}
\hline & OR & AOR Model 1 ALL [95\% CI]* & AOR Model $2[95 \% \mathrm{CI}] * *$ \\
\hline \multicolumn{4}{|l|}{ Smoking } \\
\hline never smoked & 1 & 1 & 1 \\
\hline ever smoked & $2.57[2.31-2.86]$ & $1.52[1.33-1.73]$ & $1.48[1.29-1.70]$ \\
\hline \multicolumn{4}{|l|}{ Cigarettes per day } \\
\hline 1 & 1.00 & 1 & 1 \\
\hline 2 & $1.88[0.97-3.64]$ & $1.22[0.77-1.93]$ & $1.33[0.83-2.15]$ \\
\hline $3-4$ & $1.95[1.05-3.62]$ & $1.19[0.78-1.81]$ & $1.40[0.91-2.17]$ \\
\hline $5-9$ & $2.33[1.34-4.05]$ & $1.50[1.04-2.16]$ & $1.91[1.32-2.78]$ \\
\hline $10-19$ & $3.25[1.93-5.47]$ & $1.75[1.2-2.47]$ & $2.37[1.67-3.38]$ \\
\hline $20-29$ & $3.93[2.28-6.78]$ & $2.07[1.44-2.98]$ & $3.01[2.07-4.38]$ \\
\hline $30-39$ & $7.24[3.45-15.19]$ & $3.83[2.27-6.48]$ & $6.07[3.58-10.30]$ \\
\hline $40-49$ & 6.17 [2.51-15.19] & $2.40[1.22-4.72]$ & $3.93[1.92-8.02]$ \\
\hline $50-59$ & $20.95[2.47-177.34]$ & $5.82[0.67-50.30]$ & $9.87[1.18-82.24]$ \\
\hline \multicolumn{4}{|c|}{ Alcohol consumption } \\
\hline Occasional/social & 1.00 & 1 & 1 \\
\hline Never & $0.80[0.69-0.92]$ & $1.12[0.96-1.30]$ & $1.13[0.96-1.33]$ \\
\hline Regular & $2.28[1.90-2.74]$ & $1.53[1.27-1.85]$ & \\
\hline ex & $2.00[1.72-2.32]$ & $1.66[1.43-1.94]$ & $1.44[1.22-1.70]$ \\
\hline \multicolumn{4}{|c|}{ Alcohol glasses per day } \\
\hline$<2$ & 1.00 & 1 & 1 \\
\hline $2-3$ & $1.46[1.21-1.76]$ & $1.22[1.01-1.48]$ & $1.19[0.97-1.46]$ \\
\hline $4-5$ & $1.50[1.22-1.84]$ & $1.06[0.86-1.31]$ & $1.04[0.83-1.30]$ \\
\hline $6+$ & $1.90[1.61-2.25]$ & $1.25[1.04-1.50]$ & $1.11[0.91-1.36]$ \\
\hline
\end{tabular}

* adjusted for sex and age only.

** adjusted for sex, age, education, BMI category, smoking status, self-rated health, injury history, drinking status, income and disease history (diabetes, heart disease, high cholesterol, stroke, high blood pressure).

\subsection{Health Status Indicators}

Table 4 reveals an increased risk of death for those who self-reported their overall health as anything except excellent. In the fully adjusted model though, this relationship was only statistically significant for those reporting "poor" overall health (AOR 1.96, CI 1.01-3.82). Using the obese category as a reference, in initial estimates a protective effect was found for all other body mass index categories. After adjusting for confounders however only those in the normal weight category had lower odds for mortality (AOR 0.71, CI 0.52-0.96), compared to those overweight, obese or underweight. Being a prevalent case at baseline (2005) of diabetes, hypertension, high cholesterol, ischaemic heart disease, stroke or liver disease associated positively with mortality in our unadjusted model. In the final (adjusted) model previous diagnoses of diabetes (AOR 2.46 for type I and AOR 2.14 for type II) high blood pressure (AOR 1.32), liver (AOR 1.37) and kidney (AOR 1.42) disease had statistically significant associations with mortality. Having experienced injury in the 12 months preceding the baseline survey also heightened mortality risk. In the fully adjusted model having experienced one or more injuries in the 12 months preceding the baseline survey was significantly associated with mortality (AOR 1.26 [1.01-1.57]). We also tested a range of additional health status indicators including having previously being diagnosed with a range of diseases including various types of cancer, malaria, dengue fever and tuberculosis, but none were found to have associations with mortality risk (data not shown). 
Table 4. Health status in 2005 and all-cause mortality

\begin{tabular}{|c|c|c|c|}
\hline & OR & AOR Model 1 ALL [95\% CI]* & AOR Model 2 [95\%CI]** \\
\hline \multicolumn{4}{|l|}{ Self-rated health } \\
\hline Excellent & 1 & 1 & 1 \\
\hline Very good & $0.99[0.72-1.38]$ & $1.01[0.73-1.42]$ & $1.09[0.76-1.55]$ \\
\hline Good & $0.98[0.72-1.34]$ & $1.04[0.76-1.42]$ & $1.05[0.75-1.47]$ \\
\hline Fair & $1.11[0.81-1.52]$ & $1.25[0.90-1.72]$ & $1.19[0.84-1.68]$ \\
\hline Poor & $1.38[0.94-2.01]$ & $1.64[1.12-2.40]$ & $1.50[0.99-2.26]$ \\
\hline Very poor & $1.81[0.98-3.33]$ & $2.20[1.19-4.07]$ & $1.96[1.01-3.82]$ \\
\hline \multicolumn{4}{|l|}{ Body Mass Index } \\
\hline Obese II & 1 & 1 & 1 \\
\hline Obese I & $0.39[0.29-0.53]$ & $0.82[0.60-1.12]$ & $0.88[0.63-1.23]$ \\
\hline Overweight & $0.50[0.38-0.65]$ & $0.70[0.54-0.92]$ & $0.83[0.62-1.10]$ \\
\hline Normal & $0.65[0.49-0.85]$ & $0.59[0.45-0.79]$ & $0.71[0.52-0.96]$ \\
\hline Underweight & $0.78[0.59-1.04]$ & $0.65[0.49-0.86]$ & $0.75[0.55-1.01]$ \\
\hline \multicolumn{4}{|c|}{ Disease prevalent (2005) - not prevalent as reference } \\
\hline Diabetes (type 1) & $6.60[4.10-10.63]$ & $3.74[2.29-6.13]$ & $2.46[1.45-4.65]$ \\
\hline Diabetes (type 2) & $5.21[3.95-6.88]$ & $2.26[1.69-3.03]$ & $2.14[1.56-2.96]$ \\
\hline High cholesterol & $1.69[1.45-1.97]$ & $0.92[0.78-1.08]$ & $0.88[0.73-1.05]$ \\
\hline High blood pressure & $2.61[2.20-3.10]$ & $1.40[1.17-1.68]$ & $1.32[1.08-1.62]$ \\
\hline Ischaemic heart disease & $3.82[2.45-5.95]$ & $2.25[1.42-3.56]$ & $1.61[0.95-2.73]$ \\
\hline Stroke & $3.47[1.89-6.38]$ & $2.12[1.13-3.96]$ & $1.41[0.70-2.73]$ \\
\hline Liver disease & $2.00[1.62-2.47]$ & $1.42[1.15-1.77]$ & $1.37[1.09-1.72]$ \\
\hline Kidney disease & $1.86[1.45-2.39]$ & $1.72[1.33-2.21]$ & $1.42[1.07-1.87]$ \\
\hline \multicolumn{4}{|c|}{ Number of injuries in past 12 months } \\
\hline None & 1 & 1 & 1 \\
\hline One & $1.43[1.22-1.66]$ & $1.40[1.20-1.64]$ & $1.31[1.11-1.55]$ \\
\hline Two or more & $1.46[1.19-1.79]$ & $1.48[1.21-1.82]$ & $1.26[1.01-1.57]$ \\
\hline
\end{tabular}

* adjusted for sex and age only.

** adjusted for sex, age, education, BMI category, smoking status, self-rated health, injury history, drinking status, income and disease history (diabetes, heart disease, high cholesterol, stroke, high blood pressure).

\section{Discussion}

This study presents the findings of an 11-year longitudinal investigation into risk factors for mortality in a large nationwide cohort study of Open University students embedded in the general population of Thailand. The trends observed allow us to detect patterns expected to involve the whole population in the near future. With injury and non-communicable diseases now accounting for the largest number of deaths in the country identifying modifiable risk factors is a pressing need. Our analyses have identified higher income, education and female sex as having the strongest protective effects against mortality. In terms of predictors of mortality the strongest effects were found for regular alcohol consumption, heavy smoking and high body mass index.

The outcomes from this study support other global and international literature on risk factors for all-cause mortality. This is particularly the case for alcohol consumption, smoking and prevalent high blood pressure which have been well established as the main global risk factors (World Health Organization, 2009). One association still debated in the literature is the role of excess BMI in predicting all-cause mortality. Some recent Western studies have suggested that overweight $(\mathrm{BMI}>25)$, but not obese $(>30)$, status may provide some protective effect, while 
categorical obesity increases risk (Flegal et al., 2013). However these findings have since been critiqued on methodological and classification grounds by other studies which have found, as has this study, an increased, though modest, risk of mortality is found in both the overweight and obese BMI groups (Di Angelantonio et al., n.d.; Yu, Ley, Manson, \& et al., 2017). Notably in our study increased mortality risk appears at a lower level of BMI ( $>23)$ supporting the Asian classification of excess body size beginning at BMI of 23 (Thaikruea, Seetamanotch, \& Seetamanotch, 2006).

Also of interest is the protective effect of urban migration found in our study. Much other literature reporting on low and middle income countries have found increases in sedentary lifestyles, unhealthy diets and environmental risks associated with urbanization leading to increased health and mortality risk (Allender et al., 2010; Low, Lee, \& Samy, 2014; Tan, 2011). However it appears from our results that the benefits of urbanization in terms of increased access to health services and health education may outweigh other less beneficial influences of living in urban areas. There is some possibility also that the particular education profile of our participants may mean they are more easily able to take advantage of the health benefits of urban living. However lower mortality rates in Bangkok at least have been observed in other Thai studies of the general population (Odton, Choonpradub, \& Bundhamcharoen, 2010)

The identification of higher education as being one of the strongest protective factors against mortality also agrees with much of the extant literature. Particularly in low and middle income countries provision of universal schooling has been found to be one of the strongest drivers of reductions in mortality. Education has been associated with health literacy, health-care seeking behaviour and reductions in health risk behaviours in terms of smoking, alcohol consumption and physical activity. These links between education and reduced mortality have been found to exist independent of individual or national income levels (Baker, Leon, Smith Greenaway, Collins, \& Movit, 2011; Kc \& Lentzner, 2010). Although the protective effect of being in the top two income categories was stronger than that of being in the highest education category our study was made up of a group of Open University students, most of whom had at least completed high school. If we had compared our cohort members with the general Thai population, a large proportion of whom have not completed high school, the effects of education may have been stronger.

The risk of mortality associated with previous injury history is also significant but difficult to definitively explain in terms of mechanism. There are several possible explanations. Firstly there are some individuals who are exposed to risk of injury, and other negative health impacts, through patterns of behaviour or through living in a high risk environment. These individuals identified as having high injury frequency prior to baseline may also be at higher risk of subsequent injury mortality. However previous TCS analyses have not found injury history to be a predictor of injury mortality. Instead injury mortality is predicted by other risk taking behaviours such as alcohol consumption and smoking (Yiengprugsawan, Berecki-Gisolf, Bain, et al., 2014). Another possible explanation is that the impact of injury results in worsening physical and mental health. These impacts may then lead to increased risk of mortality from causes not immediately caused by the injury itself. This concept has some evidence in support, including from other Thai Cohort Study analyses which examined the long term mental and physical health impact of injury (Yiengprugsawan, Berecki-Gisolf, McClure, et al., 2014). Studies in other settings have also found a long term increased risk of premature mortality after injury, but not caused directly by the injury, with cardiovascular disease being a common cause of death (McMillan \& Teasdale, 2007).

The strengths of this study lie in the size of the cohort, and its diversity with participants residing in communities in all regions of the country and having ages ranging from 15 to 87 in 2005. The cohort members were accurate and cooperative in responding to the questionnaire. As distance learning Open University students they also have special skills for exchanging sophisticated information by mail. This population shares many other important characteristics with the general Thai population including similar modest incomes, ethnicity and religion. Another strength is the comprehensive 20-page baseline questionnaire which collected information on a wide array of social and health characteristics allowing the testing of many risk factors and also allowing the elimination of potential confounders. The study setting in Thailand is also important as the coverage and completeness of death registration there has been found to be amongst the highest in the region with some estimates of up to $95 \%$ of deaths being registered (Prasartkul \& Vapattanawong, 2006). This means that we can be confident that all deaths of cohort members are being captured.

We acknowledge some limitations of the study. Despite the large age range of cohort members and similar median age to the general population, the cohort age distribution is younger overall. And cohort members are more highly educated than the general population. Also, all variables except mortality status are self-reported allowing for some amount of measurement error. Several validation studies however have been carried out among cohort 
members and have shown our measures are sufficiently accurate for height and weight (Lim, Seubsman, \& Sleigh, 2009), diabetes (Papier et al., 2017), and hypertension (Thawornchaisit, de Looze, Reid, Seubsman, \& Sleigh, 2014) indicating reliability of self-report. Analyses have been limited to all-cause mortality for this report. Further research will investigate the causes of mortality in the cohort and will start to establish potential causal pathways between the risk factors identified here and the causes of death. This will be particularly important for developing and testing interventions in response to the findings. Finally, the favoured method for calculating mortality risk in longitudinal studies is to use Cox Proportional Hazard models to calculate Hazard Ratios. For this study we did not collect data on the exact time of beginning of exposure to the risk factor. This means we could not calculate an exact survival time variable for the analysis. However for relatively rare events such as mortality in this cohort Odds Ratios will be close in value to the Hazard Ratios.

\section{Conclusions}

The results of this study enhance the evidence base regarding mortality risk in Thailand and provide locally relevant data for Thai health policy response. The current ongoing transition from infectious to non-communicable disease along with substantive socio-demographic change require such local data. Our results identify the need for Thailand to continue and expand its successful tobacco control program as well as to address the increasing rates of alcohol consumption in the country. The identification of education as a strong protective factor against premature mortality is particularly important in the Thai context. Although our cohort members have almost all completed high school, this figure is only around $20 \%$ among the general population. This indicates the importance of continued investment in education in order to continue Thailand's reduction in mortality into the future.

\section{Funding}

This study was supported by the International Collaborative Research Grants Scheme with joint grants from the Wellcome Trust UK (GR071587MA) and the Australian National Health and Medical Research Council (268055), and as a global health grant from the NHMRC (585426).

\section{Acknowledgements}

We thank the staff at Sukhothai Thammathirat Open University (STOU) who assisted with student contact, and the STOU students who are participating in the cohort study. We also thank the Thai Ministry of Interior for mortality data linkage.

\section{Competing Interests Statement}

The authors declare that there are no competing or potential conflicts of interest.

\section{References}

Allender, S., Lacey, B., Webster, P., Rayner, M., Deepa, M., Scarborough, P., . . Mohan, V. (2010). Level of urbanization and noncommunicable disease risk factors in Tamil Nadu, India. Bulletin of the World Health Organization, 88, 297-304. https://doi.org/10.2471/BLT.09.065847

Angkurawaranon, C., Wattanatchariya, N., Doyle, P., \& Nitsch, D. (2013). Urbanization and Non-communicable disease mortality in Thailand: an ecological correlation study. Tropical Medicine and International Health, 18(2), 130-140. https://doi.org/10.1111/tmi.12038

Baker, D. P., Leon, J., Smith Greenaway, E. G., Collins, J., \& Movit, M. (2011). The Education Effect on Population Health: A Reassessment. Population and Development Review, 37(2), 307-332. https://doi.org/10.1111/j.1728-4457.2011.00412.x

Barry, V. W., Baruth, M., Beets, M. W., Durstine, J. L., Liu, J., \& Blair, S. N. (2014). Fitness vs. Fatness on All-Cause Mortality: A Meta-Analysis. Progress in Cardiovascular Diseases, 56(4), 382-390. https://doi.org/10.1016/j.pcad.2013.09.002

Danaei, G., Finucane, M. M., Lin, J. K., Singh, G. M., Paciorek, C. J., Cowan, M. J., . . Ezzati, M. (n.d.). National, regional, and global trends in systolic blood pressure since 1980: systematic analysis of health examination surveys and epidemiological studies with 786 country-years and 5.4 million participants. The Lancet, 377(9765), 568-577. https://doi.org/10.1016/S0140-6736(10)62036-3

Danaei, G., Finucane, M. M., Lu, Y., Singh, G. M., Cowan, M. J., Paciorek, C. J., . . Ezzati, M. (2011). National, regional, and global trends in fasting plasma glucose and diabetes prevalence since 1980: systematic analysis of health examination surveys and epidemiological studies with 370 country-years and 2.7 million participants. The Lancet, 378(9785), 31-40. https://doi.org/10.1016/S0140-6736(11)60679-X

Di Angelantonio, E., Bhupathiraju, S. N., Wormser, D., Gao, P., Kaptoge, S., de Gonzalez, A. B., . . Hu, F. B. 
(n.d.). Body-mass index and all-cause mortality: individual-participant-data meta-analysis of 239 prospective studies in four continents. The Lancet, 388(10046), 776-786. https://doi.org/10.1016/S0140-6736(16)30175-1

Ezzati , M., \& Riboli, E. (2013). Behavioral and Dietary Risk Factors for Noncommunicable Diseases. New England Journal of Medicine, 369(10), 954-964. https://doi.org/10.1056/NEJMra1203528

Faramnuayphol, P., Chongsuvivatwong, V., \& Pannarunothai, S. (2008). Geographical variation of mortality in Thailand. Journal of the Medical Association of Thailand, 91(9), 1455-1460.

Farzadfar, F., Finucane, M. M., Danaei, G., Pelizzari, P. M., Cowan, M. J., Paciorek, C. J., . . Ezzati, M. (2011). National, regional, and global trends in serum total cholesterol since 1980: systematic analysis of health examination surveys and epidemiological studies with 321 country-years and 3.0 million participants. The Lancet, 377(9765), 578-586. https://doi.org/10.1016/S0140-6736(10)62038-7

Finucane, M. M., Stevens, G. A., Cowan, M. J., Danaei, G., Lin, J. K., Paciorek, C. J., . . Ezzati, M. (2011). National, regional, and global trends in body-mass index since 1980: systematic analysis of health examination surveys and epidemiological studies with 960 country-years and $9 \cdot 1$ million participants. The Lancet, 377(9765), 557-567. https://doi.org/10.1016/S0140-6736(10)62037-5

Flegal, K. M., Kit, B. K., Orpana, H., \& Graubard, B. I. (2013). Association of all-cause mortality with overweight and obesity using standard body mass index categories: A systematic review and meta-analysis. JAMA, 309(1), 71-82. https://doi.org/10.1001/jama.2012.113905

Kc, S., \& Lentzner, H. (2010). The effect of education on adult mortality and disability: a global perspective. Vienna Yearbook of Population Research, 8, 201-235. https://doi.org/10.1553/populationyearbook2010s201

Knoops, K. T., de Groot, L. C., Kromhout, D., Perrin, A. E., Moreiras-Varela, O., Menotti, A., \& van Staveren, W. A. (2004). Mediterranean diet, lifestyle factors, and 10-year mortality in elderly European men and women: the HALE project. JAMA, 292(12), 1433-1439. https://doi.org/10.1001/jama.292.12.1433

Lim, L., Seubsman, S., \& Sleigh, A. (2009). Validity of self-reported weight, height and body mass index among university students in Thailand. Population Health Metrics, 7(15). https://doi.org/10.1186/1478-7954-7-15

Low, W.-Y., Lee, Y.-K., \& Samy, A. L. (2014). Non-communicable diseases in the Asia-Pacific region: Prevalence, risk factors and community-based prevention. International Journal of Occupational Medicine and Environmental Health. https://doi.org/10.2478/s13382-014-0326-0

Mahapatra, P., Shibuya, K., Lopez, A. D., Coullare, F., Notzon, F. C., Rao, C., \& Szreter, S. (2007). Civil registration systems and vital statistics: Successes and missed opportunities. The Lancet, 370(9599), 1653-1663. https://doi.org/10.1016/S0140-6736(07)61308-7

McMillan, T. M., \& Teasdale, G. M. (2007). Death rate is increased for at least 7 years after head injury: a prospective study. Brain, 130(10), 2520-2527. https://doi.org/10.1093/brain/awm185

Papier, K., Jordan, S., Bain, C., D'Este, C., Thawornchaisit, P., Seubsman, S., \& Sleigh, A. (2017). Validity of self reported diabetes in a cohort of Thai adults. Global Journal of Health Science, 9(7). https://doi.org/10.5539/gjhs.v9n7p1

Prasartkul, P., \& Vapattanawong, P. (2006). The completeness of death registration in Thailand: evidence from demographic surveillance system of the Kanchanaburi project. World Health and Population, 8(3), 43-51. https://doi.org/10.12927/whp.2006.18054

Reedy, J., Krebs-Smith, S. M., Miller, P. E., Liese, A. D., Kahle, L. L., Park, Y., \& Subar, A. F. (2014). Higher Diet Quality Is Associated with Decreased Risk of All-Cause, Cardiovascular Disease, and Cancer Mortality among Older Adults. The Journal of Nutrition, 144(6), 881-889. https://doi.org/10.3945/jn.113.189407

Seubsman, S.-a., Kelly, M., Sleigh, A., Peungson, J., Chokkanapitak, J., \& Vilainerun, D. (2011). Methods used for successful follow-up in a large scale national cohort study in Thailand. BMC Research Notes, 4(1), 166. https://doi.org/10.1186/1756-0500-4-166

Seubsman, S., Yiengprugsawan, V., \& Sleigh, A. (2012). A large national Thai Cohort Study of the Health-Risk Transition based on Sukhothai Thammathirat Open University students. ASEAN Journal of Open and Distance Learning, 4(1), 58-69.

Sleigh, A., Seubsman, S., Bain, C., \& Team, a. t. T. C. S. (2008). Cohort profile: the Thai cohort of 87,134 Open University students. International Journal of Epidemiology, 37(2), 266-272. 
https://doi.org/10.1093/ije/dym161

Sritara, P., Cheepudomwit, S., Chapman, N., Woodward, M., Kositchaiwat, C., Tunlayadechanont, S., . . . Yipintsoi, T. (2003). Twelve-year changes in vascular risk factors and their associations with mortality in a cohort of 3499 Thais: the Electricity Generating Authority of Thailand Study. International Journal of Epidemiology, 32(3), 461-468. https://doi.org/10.1093/ije/dyg105

Tan, D. A. (2011). Changing disease trends in the Asia-Pacific. Climacteric, 14(5), 529-534. https://doi.org/10.3109/13697137.2011.555886

Tanomsup, S., Aekplakorn, W., Sritara, P., Woodward, M., Yamwong, S., Tunlayadechanont, S., .. . Rajatanavin, R. (2007). A Comparison Of Components of Two Definitions of the Metabolic Syndrome Related to Cardiovascular Disease and All-Cause Mortality in a Cohort Study in Thailand. Diabetes Care, 30(8), 2138-2140. https://doi.org/10.2337/dc07-0388

Tawatsupa, B., Dear, K., Kjellstrom, T., \& Sleigh, A. (2014). The association between temperature and mortality in tropical middle income Thailand from 1999 to 2008. International Journal of Biometeorology, 58(2), 203-215. https://doi.org/10.1007/s00484-012-0597-8

Thaikruea, L., Seetamanotch, W., \& Seetamanotch, S. (2006). Appropriate cut-off level of BMI for screening in Thai adults. Journal of the Medical Association of Thailand, 89(12), 2123-2128.

Thawornchaisit, P., de Looze, F., Reid, C., Seubsman, S., \& Sleigh, A. (2014). Validity of self-reported hypertension: findings from the Thai Cohort Study compared to physician telephone interview. Global Journal of Health Science, 6(2), 1-11.

Woodward, M., Peters, S. A. E., Batty, G. D., Ueshima, H., Woo, J., Giles, G. G., . . Vathesatogkit, P. (2015). Socioeconomic status in relation to cardiovascular disease and cause-specific mortality: a comparison of Asian and Australasian populations in a pooled analysis. BMJ Open, 5(3). https://doi.org/10.1136/bmjopen-2014-006408

World Health Organization. (2009). Global Health Risks: mortality and burden of disease attributable to selected major risks. Retrieved from Geneva:

Yiengprugsawan, V., Berecki-Gisolf, J., Bain, C., McClure, R., Seubsman, S.-a., \& Sleigh, A. C. (2014). Predictors of injury mortality: findings from a large national cohort in Thailand. BMJ Open, 4(6). https://doi.org/10.1136/bmjopen-2013-004668

Yiengprugsawan, V., Berecki-Gisolf, J., McClure, R., Kelly, M., Seubsman, S.-a., Sleigh, A. C., \& the Thai Cohort Study, T. (2014). The Effect of Injuries on Health Measured by Short Form 8 among a Large Cohort of Thai Adults. PloS One, 9(2), e88903. https://doi.org/10.1371/journal.pone.0088903

Yu, E., Ley, S. H., Manson, J. E., \& et al. (2017). WEight history and all-cause and cause-specific mortality in three prospective cohort studies. Annals of Internal Medicine, 166(9), 613-620. https://doi.org/10.7326/M16-1390

\section{Copyrights}

Copyright for this article is retained by the author(s), with first publication rights granted to the journal.

This is an open-access article distributed under the terms and conditions of the Creative Commons Attribution license (http://creativecommons.org/licenses/by/4.0/). 